\title{
IMPACT OF UPSTREAM HYDROPOWER DAMS AND CLIMATE CHANGE ON HYDRODYNAMICS OF VIETNAMESE MEKONG DELTA
}

\author{
Sameh KANTOUSH${ }^{1}$, Doan Van BINH ${ }^{2}$, Tetsuya SUMI ${ }^{3}$ and La Vinh TRUNG ${ }^{4}$ \\ ${ }^{1}$ Member of JSCE, Dr. of Eng., Associate Professor, Water Resources Research Center, Disaster Prevention Research \\ Institute, Kyoto University (Goka-sho, Uji-shi, 611-0011, Japan) \\ E-mail:kantoush.samehahmed.2n@kyoto-u.ac.jp \\ 2 Member of JSCE, Doctoral Student, Water Resources Research Center, Disaster Prevention Research Institute, Kyoto \\ University (Goka-sho, Uji-shi, 611-0011, Japan) \\ E-mail:binhdv@tlu.edu.vn \\ ${ }^{3}$ Member of JSCE, Dr. of Eng., Professor, Water Resources Research Center, Disaster Prevention Research Institute, \\ Kyoto University (Goka-sho, Uji-shi, 611-0011, Japan) \\ E-mail:sumi.tetsuya.2s@kyoto-u.ac.jp \\ ${ }^{4}$ Ph.D., Faculty of Civil Engineering, Thuyloi University-Second Base \\ (No.2, Truong Sa Street, Ward 17, Binh Thanh District, Ho Chi Minh City, Vietnam) \\ E-mail:trunglv@tlu.edu.vn
}

Between 2015 and 2016, Vietnamese Mekong Delta (VMD) has undergone the most severe drought event over the last 90 years, causing damages to agriculture, aquaculture, and fresh water suply. Moreover, upstream Mekong River development by constructing hydropower dams will magnify the severity to the region. This research therefore aims at summarizing some damaged information caused by drought event 2015-2016 and analyzing the impacts of eleven proposed mainstream dams in Thailand, Lao PDR, and Cambodia on hydrology of Vietnamese Mekong Delta under the effect of sea level rise. Results show that the flow discharge is reduced by maximum $14.9 \%$ whereas the maximum increase in water level exceeds $220 \%$. This leads to more intrusion of saltwater into the delta and reduction of fine sediment and natural nutrients settling in floodplains.

Key Words : drought, sea level rise, saltwater intrusion, mainstream dams

\section{INTRODUCTION}

The Mekong River (MR), 4,880km long, ranks as the $12^{\text {th }}$ longest river worldwide ${ }^{1)}$. The Vietnamese Mekong Delta (VMD) is located at the lowermost of MR and considered as the rice bowl of Vietnamese people ${ }^{2), 3)}$. The total area of VMD is 39,000 $\mathrm{km}^{2}$, stretching from Vietnam-Cambodia border, several kilometers upstream of Tan Chau and Chau Doc gauging stations, to the East Sea (Fig. 1). Tien and Hau Rivers (names of Mekong and Bassac Rivers in Vietnamese territory) are the two main waterways in VMD, of 250 and $220 \mathrm{~km}$ long respectively. The VMD has a highly complex channel network with a total length of around $87,500 \mathrm{~km}$. Annually, the Upper Mekong (UM) provides an

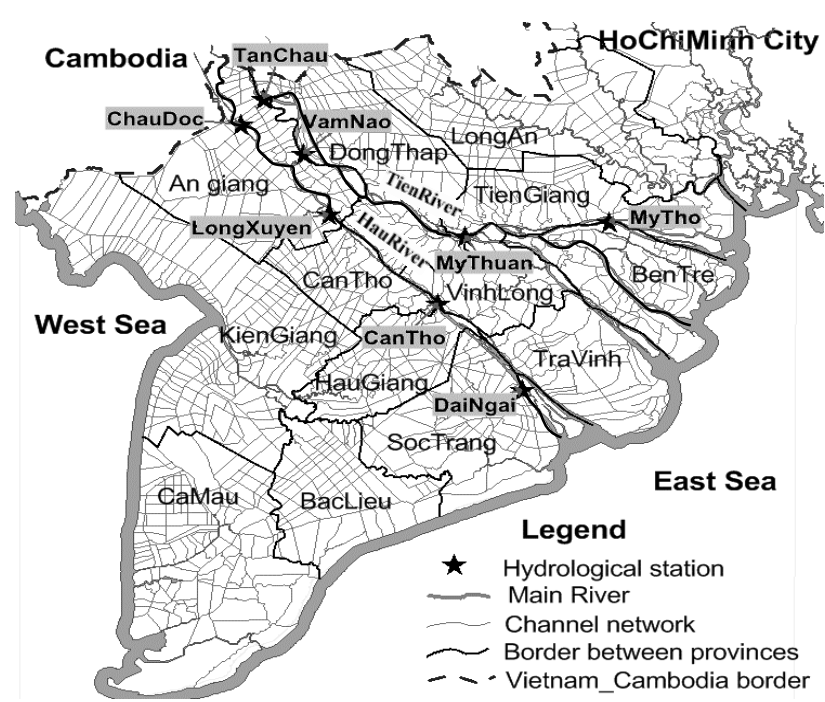

Fig. 1 Study area - Vietnamese Mekong Delta. 


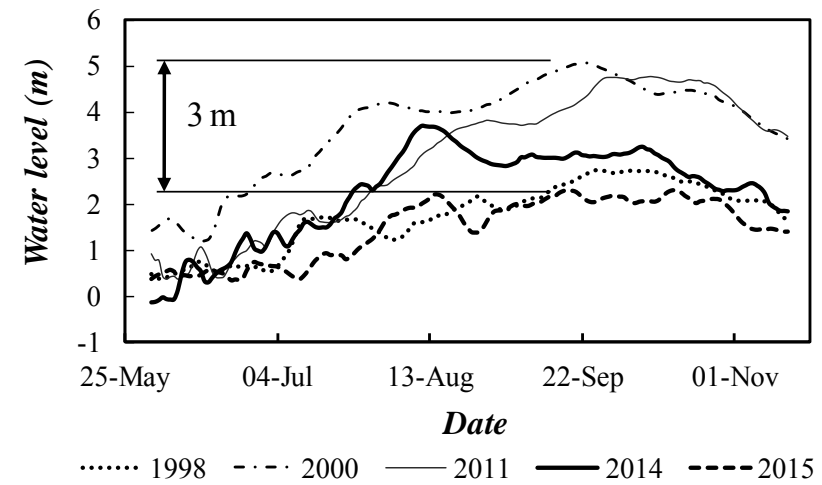

Fig. 2 Measured water level during flood season at Tan Chau station.

abundant amount of fine sediment that settles throughout the VMD through a dense network of distributaries. The VMD is therefore one of the most productive agro-aquaculture and fisheries worlwilde ${ }^{3)}$.

However, these plentiful resources are under threat due to dam construction projects in the upper part of the MR. Such impacts were reported by DHI and $\mathrm{HDR}^{4}$ that reduction in discharges at Tan Chau and Chau Doc are $1.9 \%$ and $2.5 \%$ respectively in between January to May and $0.5 \%$ in June. At the basin scale, one hundred and thirty-three (133) hydropower dams have been built or planned ${ }^{5}$, with six dams operating already in China and eleven mainstream dams being planned in Thailand, Lao PDR, and Cambodia ${ }^{4}$. Hydropower dams reduce the variability of water flow and sediment budget in VMD because a proportion of flow and sediment is stored inside of reservoirs. Moreover, fluctuation of water level is reduced because of the increasing dry season flow and decreasing wet season flow. This induces detrimental impacts on geomorphology features, nutrients, ecosystem, fish passage and river connectivity in $\mathrm{VMD}^{6}$.

\section{RECENT DROUGHT EVENT (2015-2016)}

River-damming along with the effect of El Nino, have induced the most severe drought over 90 years in 2015-2016. All provinces in VMD have been impacted by this drought event. The measured water levels were at their lowest values since 1926, even much lower than those measured in the drought year of 1998 (Fig. 2). The figure shows a reduction of $3 \mathrm{~m}$ by comparing water level on 22 of September 2000 and 2015. Correspondingly, sediment concentrations in 2015 were lower compared to precedent years (one fourth of 2011) (Fig. 3). For these considerations, in the framework of JASTIP project ${ }^{7)}$ (Japan-ASEAN Science, Technology and Innovation Platform) we established a project to study the impact of hydropower development in the UM on hydrology, sediment, and salinity changes in the Lower Mekong (LM) with special focus on VMD.

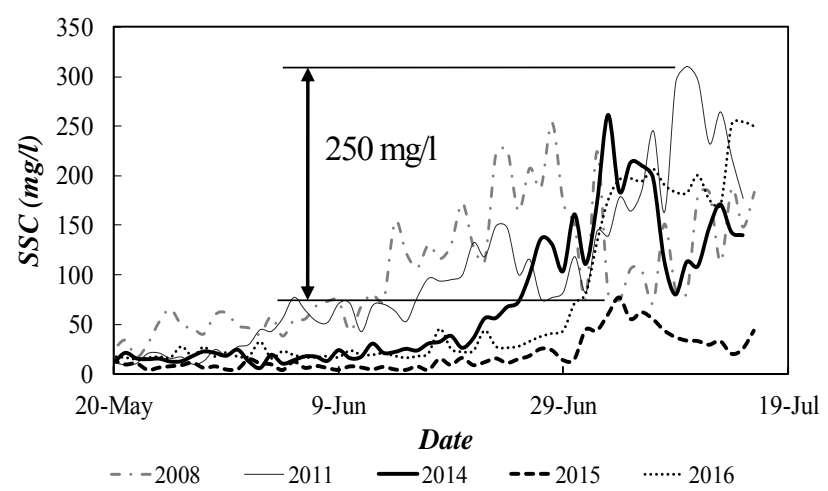

Fig. 3 Suspended sediment concentration at Vam Nao station.

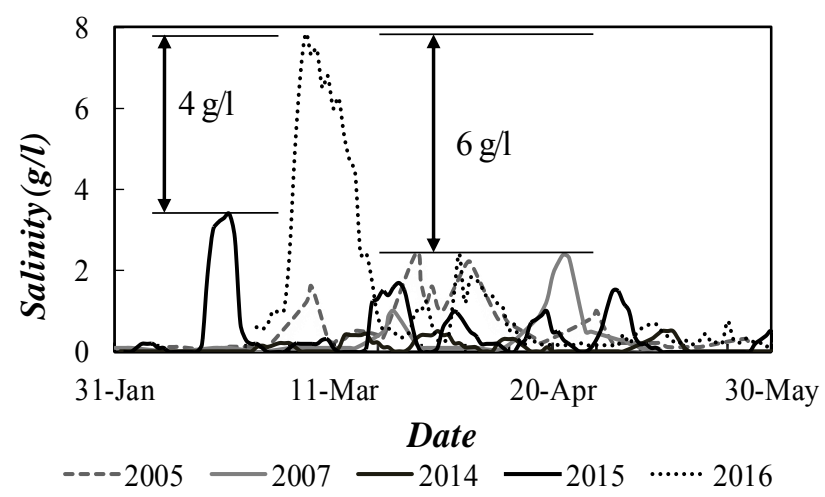

Fig. 4 Salinity concentration at An Lac Tay station.

Under this project, suspended sediment and salinity concentrations are continuously measured at several locations in Tien and Hau Rivers since February 2016 (Fig. 1).

The drought event in 2015-2016 was accompanied by saltwater intrusion in the VMD. Saltwater has intruded $45-65 \mathrm{~km}$ in Tien River and $55-60 \mathrm{~km}$ in Hau River, which is $20-25 \mathrm{~km}$ further than seasonal average values. Salinity concentrations at An Lac Tay (located 50km from the East Sea - Fig. 1) in 2015 and 2016 are much higher than recorded values in previous years (Fig. 4). The figure shows that salinity concentration of 2016 is $6 \mathrm{~g} / 1$ higher than that of 2005 and 2007. Also, salinity intrusion began approximately two months earlier than average that causes serious damages to agriculture and livelihoods of people in the Delta. By the end of 2015, about 159,000 hectare (ha) paddy fields were damaged; around 195,217 households with approximately 976,000 people lacked fresh water for daily consumption.

It is obvious that drought will become extremely serious in case more dams are built in the UM. Several questions arise therefore:

(1) What would be the impacts of upstream development activities on flow and sediment budget in the VMD?

(2) What would be the impacts of river damming on the downstream ecosystem and agro-aquaculture production during drought periods? 
Table 1 Simulation scenarios.

\begin{tabular}{|c|c|c|}
\hline Sce & Description of boundary condition & Remark \\
\hline $\begin{array}{l}\text { Baseline } \\
\text { (Sc0) }\end{array}$ & $\begin{array}{l}\text {-Upstream: discharge hydrograph of } 2015 \\
\text {-Downstream: water level stage of } 2015\end{array}$ & Without dam and without sea level rise \\
\hline $\begin{array}{l}\text { Scenario } 1 \\
\text { (Sc1) }\end{array}$ & $\begin{array}{l}\text {-Upstream: discharge hydrograph of } 2015 \text {, } \\
\text { considering } 11 \text { proposed dams } \\
\text {-Downstream: water level stage of } 2015\end{array}$ & $\begin{array}{l}\text { With dam and without sea level rise } \\
\text { - Jan. - May : }-1.9 \% \text { at TanChau and }-2.5 \% \text { at ChauDoc } \\
\text { - Jun. } \quad:-0.5 \% \text { at both TanChau and ChauDoc }\end{array}$ \\
\hline $\begin{array}{l}\text { Scenario } 2 \\
\text { (Sc2) }\end{array}$ & $\begin{array}{l}\text {-Upstream: discharge hydrograph of } 2015 \text {, } \\
\text { considering } 11 \text { proposed dams } \\
\text {-Downstream: water level stage of } 2015 \text {, } \\
\text { considering sea level rise } 47 \mathrm{~cm}\end{array}$ & $\begin{array}{l}\text { With dam and with sea level rise } \\
\text {-Jan. - May : }-1.9 \% \text { at TanChau and }-2.5 \% \text { at ChauDoc } \\
\text { - Jun. } \quad:-0.5 \% \text { at both TanChau and ChauDoc } \\
\text {-Water level of } 2015+47 \mathrm{~cm}(\text { high emission scenario - } \\
\left.\text { A1FI - increasing } 5.5 \mathrm{~mm} / \text { year }^{8)}\right)\end{array}$ \\
\hline
\end{tabular}

(3) What happens if such impacts take place under sea level rise induced by global climate warming?

To date, there have been a few studies evaluating the impacts of hydropower dams and sea level rise on sediment dynamics ${ }^{3)}$, hydrological change ${ }^{4)}$ and flooding $^{9)}$ and even less studies pay attention on drought in VMD. Therefore, the present work addresses the expected effects of eleven planned upstream dams on the hydrology of VMD under the effect of sea level rise. To do this, a one-dimensional numerical model is used. The dry season of 2015 (from January to June) is considered as the reference event.

\section{MODEL SETUP AND SCENARIOS}

The prediction of hydrology changes in the VMD under the development of 11 dams along with sea level rise is performed using Mike 11 hydrodynamic model developed by $\mathrm{DHI}^{10)}$. The model solves the 1-D Saint Venant equations using an implicit finite difference scheme. The model was set up for the whole VMD, including 2,551 branches with 13,429 points as in Fig. 5. In the model, hourly discharges at Tan Chau and Chau Doc stations are used as upstream boundaries whereas hourly water levels at seven stations along the coast, including My Thanh, Ben Trai, Vam Kenh, Ganh Hao, Song Doc, Binh Dai, and Rach Gia are prescribed as downstream boundary conditions. One hundred and fourty-five (145) cross sections describing the geometry of Tien River from Tan Chau to My Thuan (see Fig. 1) are updated to 2014 whereas cross sections measured in 2010 are applied elswhere.

Three scenarios are used to simulate changes of hydrology in VMD (Table 1). The baseline ( $\mathrm{Sc} 0)$ refers to discharges and water levels of the drought year 2015. Scenario 1 (Sc1) considers the impact of 11 dams. In scenario 1, discharges at Tan Chau and Chau Doc are reduced by $1.9 \%$ and $2.5 \%{ }^{4)}$, respectively, in between January and May and by $0.5 \%$ in June ${ }^{4)}$ compared to the baseline (Table 1), but water levels remain unchanged. Scenario $2(\mathrm{Sc} 2)$ is similar to $\mathrm{Sc} 1$ but sea level rise is considered at the downstream ends.

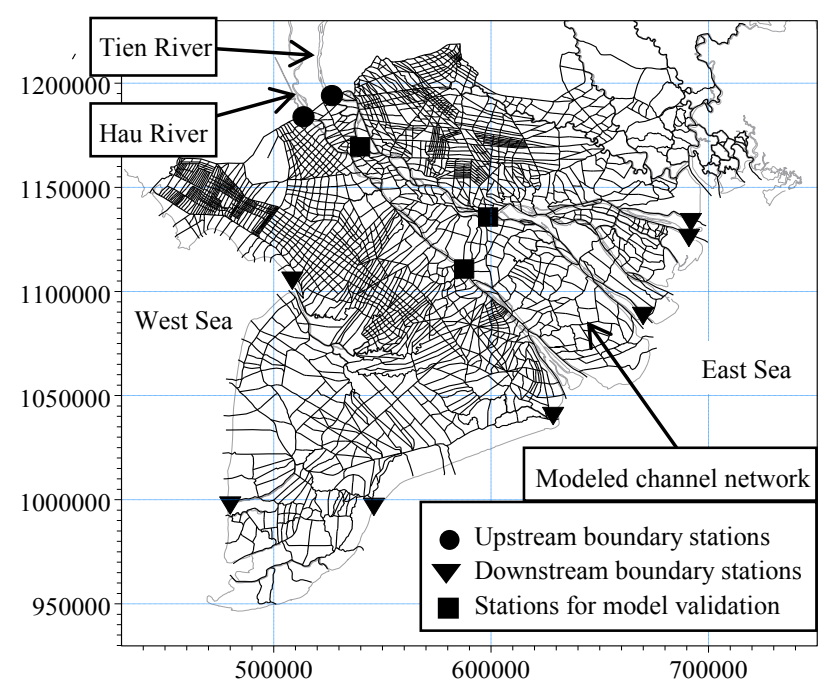

Fig. 5 1-D hydrodynamic model setup.

Table 2 Values of two performance indicators at three stations.

\begin{tabular}{|cccc|}
\hline Station & VamNao & MyThuan & CanTho \\
\hline \multicolumn{4}{c|}{ Calibration (2015) } \\
\hline $\mathbf{R}^{\mathbf{2}}$ & 0.913 & 0.936 & 0.978 \\
$\mathbf{E}_{\mathbf{f}}$ & 0.807 & 0.862 & 0.913 \\
\hline \multicolumn{4}{c|}{ Validation $(1998)$} \\
\hline $\mathbf{R}^{\mathbf{2}}$ & 0.877 & 0.97 & 0.95 \\
$\mathbf{E}_{\mathbf{f}}$ & 0.727 & 0.912 & 0.890 \\
\hline
\end{tabular}


Table 3 Average discharge reduction and water level increase within the simulated period (Jan. - Jun.) in VMD under different simulation scenarios at eight measurement stations.

\begin{tabular}{|c|c|c|c|c|c|c|c|c|}
\hline Station & TanChau & VamNao & MyThuan & MyTho & ChauDoc & LongXuyen & CanTho & DaiNgai \\
\hline \multicolumn{9}{|c|}{ Discharge reduction $\left(\mathrm{m}^{3} / \mathrm{s}\right)$} \\
\hline (Sc1-Sc0) & -63.8 & -31.6 & -27.0 & -9.6 & -13.8 & -50.6 & -50.0 & -17.1 \\
\hline $\mathbf{P}(\%)$ & -1.7 & -2.2 & -1.2 & -0.5 & -2.1 & -2.8 & -2.9 & -3.6 \\
\hline (Sc2-Sc0) & -63.8 & -24.1 & -34.8 & -16.3 & -13.8 & -213.8 & -260.2 & -22.2 \\
\hline $\mathbf{P}(\%)$ & -1.7 & -1.0 & -2.8 & -2.7 & -2.1 & -11.6 & -14.9 & -4.6 \\
\hline \multicolumn{9}{|c|}{ Water level increase $(\mathrm{cm})$} \\
\hline (Sc2-Sc0) & 0.423 & 0.436 & 0.456 & 0.467 & 0.436 & 0.452 & 0.458 & 0.467 \\
\hline $\mathbf{P}(\%)$ & 94.6 & 127.1 & 75.5 & 221.2 & 139.2 & 172.6 & 162 & 25.7 \\
\hline
\end{tabular}

According to Doyle et al. $(2010)^{8)}$, sea level increases by $5.5 \mathrm{~mm} /$ year under high emission scenario.Therefore, water levels of scenario 2 are those of 2015 increased by $47 \mathrm{~cm}$ as the total increase in water level up to the year 2100 .

\section{MODEL VALIDATION AND RESULTS}

Water levels at Vam Nao and My Thuan stations in Tien River and Can Tho station in Hau River (see Fig. 1) of the year 2015 are used to calibrate the model. The model is validated using water levels measured at the same stations during the drought year 1998. Computed versus measured water levels at Can Tho station are plotted in Fig. 6. The accuracy of the numerical results is evaluated using correlation coefficient $\left(R^{2}\right)$ and Nash-sutcliffe coefficient $\left(E_{f}\right)$ (Table 2). Based on these performance indicators, one can see that a satisfactory model-data agreement is obtained.

Hydrological parameters of VMD are directly affected by changes in the upstream discharges at Tan Chau and Chau Doc and downstream water levels along the coast. Table 3 shows the reduction in average simulated discharges and the increase in average simulated water levels within the studied period (Jan. - Jun.) under different scenarios. Moreover, Fig. 7 shows a comparison between the difference in $\mathrm{Sc} 1$ and $\mathrm{Sc} 2$. The difference between scenarios is calculated as follow in equations 1 and 2:

$$
\begin{gathered}
(S c x-S c 0)=\frac{\sum_{i=1}^{N}\left(A_{S c x_{-} i}-A_{S c 0_{-} i}\right)}{N} \\
P(\%)=\frac{\sum_{i=1}^{N}\left[\left(A_{S c x_{-} i}-A_{S c 0_{-} i}\right) / A_{S c 0_{-} i} \cdot 100\right]}{N}
\end{gathered}
$$

where: $(S c x-S c 0)$ : the difference of discharges or water levels in absolute values between scenario $x$ $(x=1$ : scenario 1 and $x=2$ : scenario 2$)$ and the baseline $(\mathrm{ScO})$; $A_{S c x_{-} i}, A_{S c 0_{-} i}$ : discharge or water level of scenario $x$ and the baseline, respectively, at day $i^{\text {th }}$; $P(\%)$ : the difference of discharge or water level between scenarios and the baseline in percentage; $N$ : number of days within Jan. - Jun. If $(S c x-S c O)$ (or $P(\%))$ is possitive, discharge or water level will increase, vice versa they will decrease.

Under the reduction of discharges at Tan Chau and Chau Doc ( $\mathrm{Sc} 1)$, flow discharges at stations Vam Nao, My Thuan and My Tho in Tien River and at Long Xuyen, Can Tho, and Dai Ngai in Hau River are reduced by 0.5 to $3.6 \%$ in average (Table 3 ). In Tien River, the maximum reduction of discharge is obtained at Tan Chau station with a mean value of $63.8 \mathrm{~m}^{3} / \mathrm{s}$, while in Hau River it is Long Xuyen station that experiences the maximum reduction $\left(50.6 \mathrm{~m}^{3} / \mathrm{s}\right)$. More seriously, discharges in VMD are even more reduced in $\mathrm{Sc} 2$ which further considers the influence of sea level rise. For example, mean discharge at Can Tho station drops by $260 \mathrm{~m}^{3} / \mathrm{s}$, corresponding to $14.9 \%$ - the maximum reduction among stations (Table 3). In contrast, water levels at all stations in VMD are increased, a clear example from My Tho station is shown in Fig. 8. Water levels in stations near the sea increase faster than those in upstream sections (Table 3). Among these, water levels at My Tho station increase the most with over $220 \%$ (Fig. 8 ).

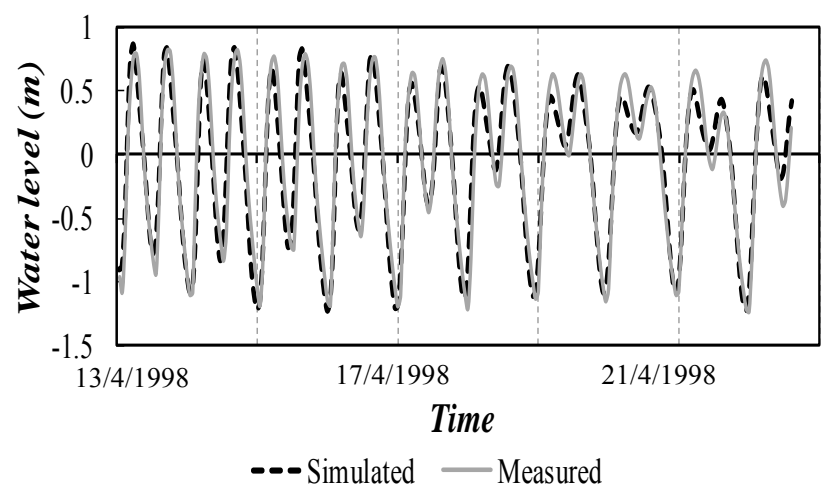

Fig. 6 Predicted and measured water levels at Can Tho station. 


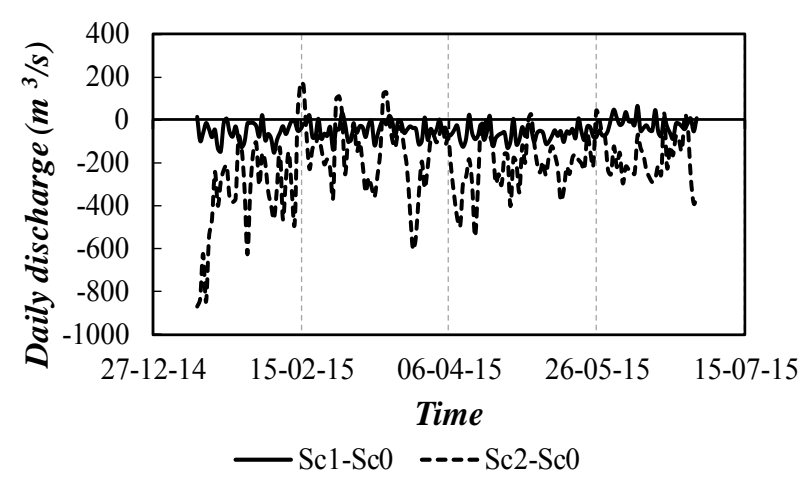

Fig. 7 Discharge reduction of scenario 1 and 2 compared to the baseline in solid and dash lines at Long Xuyen station.

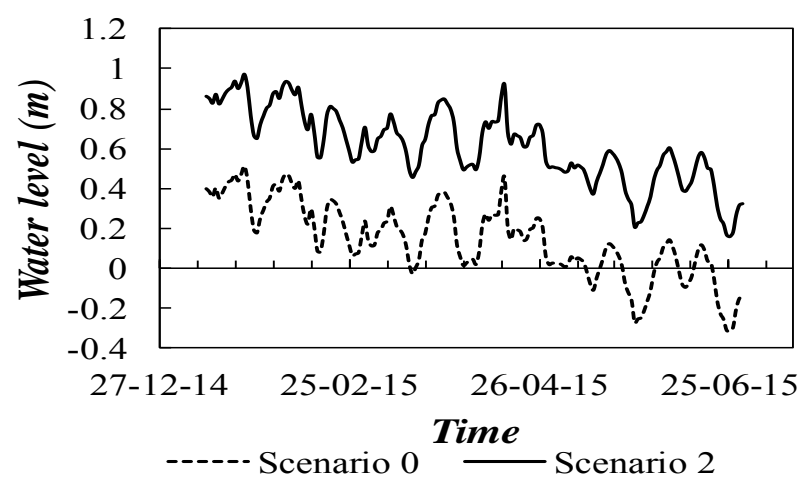

Fig. 8 Increase in water level of scenario 2 compared to the baseline at My Tho station.

\section{DISCUSSIONS}

Because of the geographical location, hydrology of VMD is strongly dependent on activities of upstream countries such as dam construction and irrigation development. To date, China has completed six dams of the Lancang cascade in the Upper Mekong Basin (UMB), in which Manwan was fully operated in 1996 and Nuozhadu in 2012 ${ }^{11)}$. Consequently, VMD has undergone a decreased trend in flow discharge (Fig. 9). Obviously, Chinese dams must be the cause of water decrease in VMD. More seriously, two drought events happened just after the first and the last dams, in 1998 and 2015.

Recently, there are other eleven dams proposed by Thailand, Lao PDR, and Cambodia in the mainstream of MR. Results from scenario 1 show that these eleven dams will cause flow discharge declining in VMD from 0.5 to 3.6\%. The Hau River experiences higher reduction than Tien River. Moreover, the further the areas from Vietnam-Cambodia border is, the more the reduction in flow discharges will be. Importantly, these proposed dams together with existed ones in China may lead to the disappearance of floods in the upper parts VMD, which is extremely crucial to livelihoods of millions of people there.

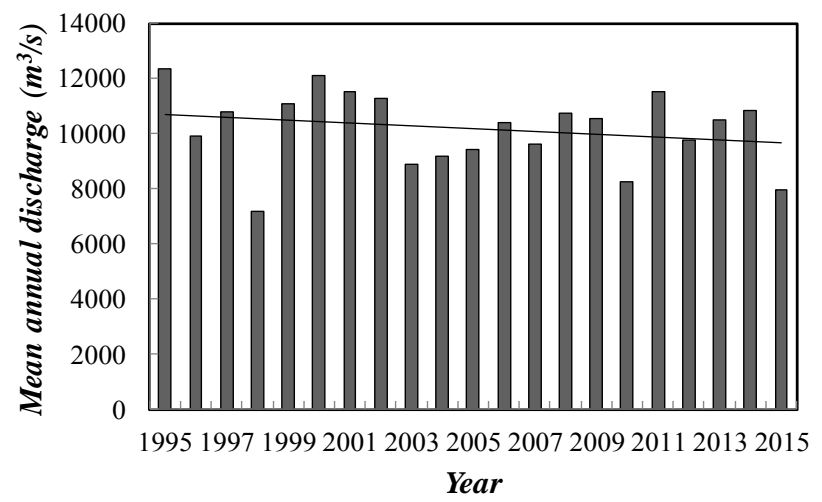

Fig. 9 Mean discharge at Tan Chau station.

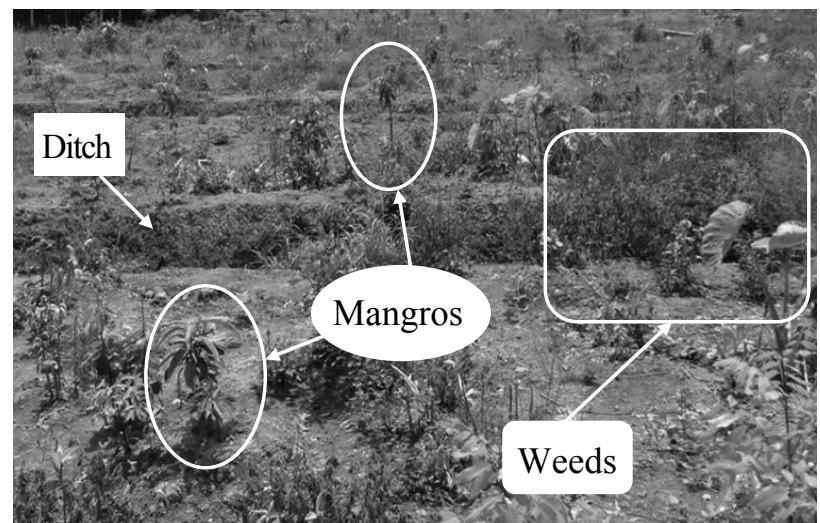

Fig. 10 Damaged fruit-garden in Ke Sach district - Soc Trang province. Died mangosteen was replaced by new mango.

Low discharge observed at the upper of VMD during the drought event of 2015-2016 caused saltwater intruding deeply into lands, thereby resulting in detrimental impacts on agriculture and aquaculture. The drought of 2015-2016 has led to total damages of 31,198.94 ha (approximately 2.2 million US dollars) in only Soc Trang province. Many regions, where paddy fields with 27,004.16 ha were affected, have reduced their agricultural productivity (Fig. 10).

As predicted by scenario 2, flow discharges are much reduced and water levels are increased in VMD (Table 3). Discharges at Can Tho station decrease the most with $14.9 \%$ while My Tho station faces an increase of more than $220 \%$ in water level. This causes saltwater significantly to intrude into the upper parts. It means that more areas, including regions having not been affected before, will be covered by saline water with higher concentration.

Sea level rise may also increase flooding in coastal regions of $\mathrm{VMD}^{9}$. Furthermore, because of decreasing discharges and increasing water levels, flow velocity will be reduced in the channels. Nutrient-rich sediment will deposit preferentially in rivers instead of conveying into floodplains that may lead to a reduction of agricultural productivity in a near future. 


\section{CONCLUSIONS AND RECOMMENDATIONS}

Many areas in VMD have been impacted by drought event in 2015-2016. Low discharge entering from the upstream end resulted in the shortage of fresh water supply for irrigation. Saltwater has intruded up to $65 \mathrm{~km}$ and $60 \mathrm{~km}$ in Tien and Hau Rivers, respectively, which is about $20-25 \mathrm{~km}$ deeper in land than average. These have caused damages to thousands of hectares of agriculture and aquaculture, corresponding to dozens of millions of US dollars. Also, livelihoods of thousands of people were endangered by lacking of fresh water for daily consumption.

The situation of drought will become more serious if eleven proposed mainstream dams in Thailand, Lao PDR, and Cambodia are constructed. This paper shows that VMD will experience a maximum reduction of flow discharge of $3.6 \%$. More dangerously, discharge will be reduced up to a maximum value of $14.9 \%$ while maximum water level increase will be more than $220 \%$ under the combined effect of $47 \mathrm{~cm}$ sea level rise and 11 mainstream dams. These allows saltwater significantly intruding into the upper parts of the Delta, even in areas having not been affected before, with higher salinity concentration. The research also predicts that flooding in coastal regions will frequently occur if sea level continues rising. In addition, rice crops are foreseen to lack fine sediment carrying abundant natural nutrients because of reduced exchange between rivers and floodplains.

In general, increase of salinity intrusion and coastal flooding, disappearance of flooding in upper VMD, and lacking of fine sediment and natural nutrients to floodplains as a result of upstream dam development and sea level rise will have tremendously negative effects on agriculture, aquaculture, irrigation and fishery. Finally, livelihoods of millions of people in VMD will be severely affected.

The authors recommend alternative design types to investors of these eleven proposed mainstream dams in Thailand, Lao PDR, and Cambodia to modify them as run-of-the-river hydropower plants. For new proposed dams in the mainstream as well as in the tributaries, the design should take into account their negative impacts on the downstream countries in order to have an integrated utilization of limited fresh water in transboundary Mekong River. Furthermore, local governments in the impacted areas by salinity intrusion should temporarily change the purpose of land use from freshwater agriculture to saltwater aquaculture if it can improve livelihoods of local people. Finally, it is necessary to urgently develop an early warning system of drought and salinity intrusion to help people actively deal with such hazards.
The impacts of upstream hydropower dams and climate change on hydrology of VMD figured out in this paper is the first-hand results based on 1-D simulation analysis. Two dimensional numerical simulations will be implemented to evaluate the impacts of these drivers on both flow regime and sediment dynamics of VMD.

ACKNOWLEDGEMENT: This research is funded by JASTIP. The authors thank Mr. Vinh (Department of Agriculture and Rural Development of Soc Trang province) for his kindly help in site visits and data sharing. We also acknowledge Dr. Kamal El Kadi of EDF for his reading and discussions about numerical simulations.

\section{REFERENCES}

1) Gupta, A., and Liew, S. C.: The Mekong from satellite imagery: A quick look at a large river, Geomorphology, Vol. 85, pp. 259-274, 2007.

2) Ziv, G., Baran, E., Nam, S., Rodríguez-Iturbe, I., and Levin, S. A.: Trading-off fish biodiversity, food security, and hydropower in the Mekong river basin, Proc. Natl. Acad. Sci, U.S.A, Vol. 109, No. 15, pp. 5609-5614, 2012.

3) Manh, N. V., Dung, N. V., Hung, N. N., Kummu, M., Merz, B., and Apel, H.: Future sediment dynamics in the Mekong delta floodplains: Impacts of hydropower development, climate change and sea level rise, Global and Planetary Change, Vol. 127, pp. 22-33, 2015.

4) DHI and HDR: Study on the impacts of mainstream hydropower on the Mekong river, impact assessment report, Volume 1 models, model setup and simulations, 332 pp., 2015.

5) Kondolf, G. M., Rubin, Z. K., and Minear, J. T.: Dams on the Mekong: cumulative sediment starvation, Water Resources Research, Vol. 50, pp. 5158-5169, 2014.

6) Beilfuss, R.: A risky climate for southern African hydro, assessing hydrological risks and consequences for Zambezi river basin dams, International Rivers, 60 pp., 2012.

7) http://jastip.org/en/project/disaster_prevention/.

8) Doyle, T., Day, R., and Micho, T.: Development of sea level rise scenarios for climate change assessment of the Mekong Delta Vietnam, U.S. Geological Survey Open File Report, 110 pp., 2010.

9) Hoa, L.T.V., Nhan, N.H., Wolanski, E., Cong, T.T., and Shigeko, H.: The combined impact on the flooding in Vietnam's Mekong River Delta of local man-made structures, sea level rise, and dams upstream in the river catchment, Estuarine, Coastal and Shelf Science, Vol. 71, pp. 110-116, 2007.

10) DHI: Mike 11: A modelling system for rivers and channels. Reference Mannual, Danish Hydraulic Institute, Denmark, 524 pp., 2009.

11) Fan, H., He, D., and Wang, H.: Environmental consequences of damming the mainstream Lancang-Mekong river: A Review, Earth-Science Reviews, Vol. 146, pp. 77-91, 2015. 